\title{
Innovative moments and change in client-centered therapy
}

\author{
MIGUEL M. GONÇALVES ${ }^{1}$, INÊS MENDES ${ }^{2}$, GRACIETE CRUZ ${ }^{1}$, ANTÓNIO P. RIBEIRO ${ }^{1}$, \\ INÊS SOUSA ${ }^{3}$, LYNNE ANGUS ${ }^{4}$, \& LESLIE S. GREENBERG ${ }^{4}$ \\ ${ }^{1}$ School of Psychology, University of Minho, Braga, Portugal; ${ }^{2}$ Research Center at the Center for Cognitive-Behavioral Studies \\ and Intervention, ISMAI, Maia, Portugal; ${ }^{3}$ Mathematics and Applications, University of Minho, Portugal $\mathbb{E}{ }^{4}$ Department of \\ Psychology, York University, Toronto, Canada
}

(Received 27 April 2010; revised 19 fanuary 2012; accepted 22 fanuary 2012)

\begin{abstract}
Previous studies have used the Innovative Moments Coding System (IMCS) to describe the process of change in Narrative Therapy (NT) and in Emotion-Focused Therapy (EFT). This study aims to extend this research program to a sample of Client-Centered Therapy (CCT). The IMCS was applied to six cases of CCT for depression to track the Innovative Moments (IMs) which are exceptions to the problematic self-narrative in therapeutic conversation. Results suggest that IMCS can be applied to CCT, allowing the tracking of IMs' emergence. The analysis based on a generalized linear model revealed that the overall amount of IMs is significantly associated with symptom improvement, which is congruent with former studies done with the IMCS.
\end{abstract}

Keywords: process research; experiential/existential/humanistic psychotherapy; innovative moments; narrative change

In psychotherapy much more takes place than the reduction of clients' symptoms and complaints. As observed long ago by Frank (1961, see Frank \& Frank, 1991), the task of psychotherapy is one of transforming clients' "maladaptive assumption systems [that] lead to demoralization" (p. 51). Frank and Frank go further by stating that "Effective psychotherapies combat demoralization by persuading patients to transform these pathogenic meanings to ones that rekindle hope, enhance mastery, heighten self-esteem, and reintegrate patients with their groups" (p. 521, italics added). The narrative perspective of this study (see Angus \& McLeod, 2004; Gonçalves, Matos, \& Santos, 2009; McAdams, 1993; Sarbin, 1986; White \& Epston, 1990) emphasizes that human beings give meaning to their lives through the construction of narratives addressed to themselves and to significant others.

A narrative perspective on Frank's above proposal suggests that both the pathogenic meanings and the new ones are structured into narrative forms. We term the pathogenic meanings (the "maladaptive assumption systems") as problematic self-narratives, and the new emerging meanings as innovative moments (IMs).
We further suggest that the emergence and accumulation of new emerging meanings or Innovative Moments (IMs) allows the construction of a new, more flexible and adaptive, self-narrative, in which the former maladaptive assumptions were revised and transformed.

A parallel can be drawn between the IMs model and the assimilation perspective from Stiles and collaborators (Osatuke \& Stiles, 2006). According to the assimilation model, people's experiences leave traces that are represented in the self as active voices. Constellations of similar or related experiences become linked, or assimilated, and form a community of voices. The community is experienced by the person as his or her usual sense of self, personality, or center of experience. Other voices, not accepted by the self, are assimilated in the process of successful therapy. Thus, the community of voices can be equated with the problematic selfnarrative, while the voices that become assimilated during therapy are akin to IMs. From this perspective, every time a non-dominant (e.g., repressed) voice is expressed an IM occurs.

In this study we investigate how IMs develop in a sample of Client-Centered Therapy (CCT) for

Correspondence concerning this article should be addressed to Miguel M. Gonçalves, University of Minho, School of Psychology, Braga, Portugal. Email: mgoncalves@psi.uminho.pt 
depression. Previous studies have analyzed IMs in Narrative Therapy (NT) with women who were victims of intimate violence (Matos, Santos, Gonçalves, \& Martins, 2009) and in EmotionFocused Therapy (EFT) with clients with major depression (Mendes et al., 2010). Despite the similarities between the EFT and CCT samples (same site, same diagnosis, and common therapeutic principles), key treatment principles differ in the two treatment approaches and we hypothesize that, given the presence of emotion-focused interventions, the CCT profile of IMs emergence will be different from the one found in EFT.

\section{Innovative Moments Coding System and a Model of Change}

The Innovative Moments Coding System (IMCS) (Gonçalves, Ribeiro, Mendes, Matos, \& Santos, 2011) provides a systematic and reliable method for the identification of IMs. IMCS allows the identification of five different types of IMs - action, reflection, protest, reconceptualization and performing change (see Table I).

1. Action IMs are new accomplishments, specific actions that are different from what the problematic self-narrative impels the person to do.

2. Reflection IMs refer to new ways of thinking and feeling, and new understandings about the implications of the problem in the client's life.

3. Protest IMs are instances in which the client actively refutes the problem, the assumptions behind it, or people that support the problematic way of functioning. This active refusal distinguishes protest from action and reflection and, although it could appear in a multitude of semantic forms, represents something that could be summarized by "I won't accept this [facet of the problem] anymore".

4. Reconceptualization IMs contain the client's description of two components: (1) the contrast between the self in the past (problematic selfnarrative) and the self in the present (emergent new meanings) and (2) the depiction of the process that allowed for this change. That is, the client not only describes the contrast between the problematic past and the new present, but also has some knowledge of how this change has occurred.

5. Performing change IMs refer to the anticipation or planning of new experiences, projects, or activities at the personal, professional, and relational level. They can also reflect the performance of change or new skills that are akin to the emergent new pattern (e.g., new projects that derive from a new self-version). They describe the consequences of the change process developed so far, such as acquiring new understandings which are viewed as useful for the future or new skills that were developed after overcoming the problematic experience. The coding of performing change implies the presence of a marker of change; that is, the client has to narrate the perception of some meaningful transformation. This feature allows us to distinguish performing change from action IMs, given that in action IMs the recognition of a meaningful previous change is absent. To clearly distinguish action from performing change the following example from an agoraphobic client might be used: successfully doing an exposure exercise would be an action IM, while going on a cruise and enjoying the trip would be a performing change IM.

It is important to emphasize that these types of IMs resulted from a preliminary study on how innovation emerges in narrative therapy (Matos \& Gonçalves, 2004), and since then diverse therapeutic modalities and complaints have been studied. The concept of IM is inspired by the notion of unique outcomes proposed by White and Epston (1990), who suggest that the transformation of problematic self-narratives is the result of clients' construction of alternative meanings (that is, unique outcomes). It is reasonable to expect that this concept could be used with other modalities of therapy, since, as emphasized above by Frank (1961/1991), all therapies aim to create alternative meanings in clients' lives. Thus, we view IMCS as a potential transtheoretical tool for studying the change process in different modalities of therapy.

After developing the IMCS we conducted two process-outcome studies (Matos et al., 2009; Mendes et al., 2010) which are briefly summarized below. In Matos et al.'s study, sessions from narrative therapy of women who had been victims of intimate violence (White \& Epston, 1990) were analyzed by means of IMCS. The results indicated that while IMs appeared both in good $(n=5)$ and in poor $(n=5)$ outcome cases, clients in the good outcome NT group spent significantly more time processing IMs in their sessions. Significant differences between good and poor outcome NT clients were found for reconceptualization and performing change IMs, while no significant differences were found for action, reflection and protest IMs.

Mendes et al. (2010) investigated IMs' evolution in six clients drawn from the York I Depression study (Greenberg \& Watson, 1998) and found a similar pattern of results. Again good outcome cases had a 
Table I. IMs with examples

\begin{tabular}{ll}
\hline Contents \\
\hline Action \\
- New coping behaviors facing anticipated or \\
- Effective resolution of unsolved problem(s); \\
- Active exploration of solutions; \\
- Restoring autonomy and self-control; \\
- Searching for information about \\
\\
the problem(s).
\end{tabular}

Reflection

Protest

Reconceptualization RC always involves two dimensions:

- Description of the shift between two positions (past and present);

- The process underlying this transformation.
- Change process - Considering the process and strategies; implemented to overcome the problem(s); references of self-worth and/or feelings of well-being (as consequences of change);

- New positions - references to new/emergent identity versions in face of the problem(s).

Criticizing the problem(s)

- Repositioning oneself towards the problem(s)

\section{Emergence of new positions}

- Positions of assertiveness and empowerment;
Examples (problematic self-narrative: depression)

C: Yesterday, I went to the cinema for the first time in months!

C: I realize that what I was doing was just not humanly possible because I was pushing myself and I never allowed myself any free time, uh, to myself ... and it's more natural and more healthy to let some of these extra activities go ...

C: I believe that our talks, our sessions, have proven fruitful, I felt like going back a bit to old times, it was good, I felt good, I felt it was worth it.
C: What am I becoming after all? Is this where I'll be getting to? Am I going to stagnate here!?

C: I am an adult and I am responsible for my life, and, and, I want to acknowledge these feelings and I'm going to let them out! I want to experience life, I want to grow and it feels good to be in charge of my own life.

C: You know ... when I was there at the museum, I thought to myself: you really are different ... A year ago you wouldn't be able to go to the supermarket! Ever since I started going out, I started feeling less depressed ... it is also related to our conversations and changing jobs ...

T: How did you have this idea of going to the museum? C: I called my dad and told him: we're going out today! $\mathrm{T}$ : This is new, isn't it?

C: Yes, it's like I tell you ... I sense that I'm different ...

$\mathrm{T}$ : You seem to have so many projects for the future now! C: Yes, you're right. I want to do all the things that were impossible for me to do while I was dominated by depression. I want to work again and to have the time to enjoy my life with my children. I want to have friends again. The loss of all the friendships of the past is something that still hurts me really deeply. I want to have friends again, to have people to talk to, to share experiences and to feel the complicity in my life again.
- Performance of change: new skills

- Re-emergence of neglected or forgotten self-versions.

Generalization into the future and other ensions of good outcomes; new situations;

- Investment in new projects as a result of the process of change;

- Investment in new relationships as a result of the process of change;

Note. From The Innovative Moments Coding System: A coding procedure for trackingchanges in psychotherapy, by Gonçalves, Ribeiro, Mendes, et al. (2011). Adapted with permission.

higher amount of overall IMs, and significant differences emerged between groups in reconceptualization and performing change IMs. No differences were found for action, reflection and protest IMs. Similar findings were also obtained in several case studies (Gonçalves, Mendes, Ribeiro, Angus, \& 
Greenberg, 2010; Ribeiro, Gonçalves, \& Ribeiro, 2009; Santos, Gonçalves, \& Matos, 2011; Santos, Gonçalves, Matos, \& Salvatore, 2009).

These studies lead us to propose a heuristic model of IM evolution that we summarize below (Gonçalves et al., 2009; Matos et al., 2009). The reader should have in mind that this model is still tentative and thus open to further revisions as new studies are developed. According to this model, in the initial stage of therapy, action and reflection are usually the first IM types to occur (see Figure 1). Action and reflection IMs are the most elementary forms of innovation, constituting signs to the client and to the therapist that distinct ways of acting, thinking and feeling are emerging in the client's life. Usually reflection IMs are much more prevalent than action IMs, at least in the modalities of therapy studied so far. Protest IMs may emerge along with action and reflection IMs or may emerge later in therapy, and they represent a more empowered position of the self towards the problematic selfnarrative, implying a strong attitudinal position against the problem's dominance in the client's life. We suggest that, although these three types of IMs represent important novelties, they appear to be insufficient for the development and sustaining of an alternative new self-narrative.

In contrast, the model suggests that reconceptualization is a key ingredient in the process of change. In the case-studies and samples analyzed, reconceptualization IMs emerge in the middle of successful therapy and continue developing until the end of the treatment. We speculate that reconceptualization IMs have several important functions in the process of change. First, they involve a contrast between the problematic self-narrative and a new way of functioning. In this sense, the first function of reconceptualization is to create a narrative contrast in the process of changing, consolidating the meaning of
IMs (e.g., action, reflection) that emerged previously. After the emergence of reconceptualization IMs, new IMs of action, reflection and protest occur, expanding the former reconceptualization IMs. That is, as the client views him or herself differently from before (reconceptualization IMs), the subsequent emergence of action, reflection and protest IMs provides further validation of the significant changes that are taking place.

Moreover, in the contrast established, the client clearly identifies him or herself with the present selfversion, somehow rejecting the problematic one and viewing it as belonging to the past. Thus, we suggest that reconceptualization's second function is to facilitate the progressive identification with a new self-narrative (Cunha, Gonçalves, Valsiner, Mendes, \& Ribeiro, in press; Gonçalves \& Ribeiro, 2012). It is important to emphasize that in successful therapy reconceptualization IMs are usually the most prevalent type of IM after the middle of the treatment, which suggests that the repetition of these IMs is central to the process of change. We speculate that the repetition is essential in facilitating progressive identification with the new self-version.

Finally, for coding reconceptualization some knowledge about the process of change, of how a person changed from one state to a new one, is needed. In our view this knowledge of how the client evolved from a past position to a new one is essential in maintaining his or her sense of continuity (Cunha et al., in press; Gonçalves \& Ribeiro, 2012; Ribeiro \& Gonçalves, 2010), guaranteeing a position of authorship to the client. This represents reconceptualization's third function - creating a sense of authorship and self's continuity. Without this element, the sense of self would be fragmentary. What we refer to here as a sense of authorship has been described by other researchers as meta-cognitive functions (Dimaggio, 2006), and has been considered central in the

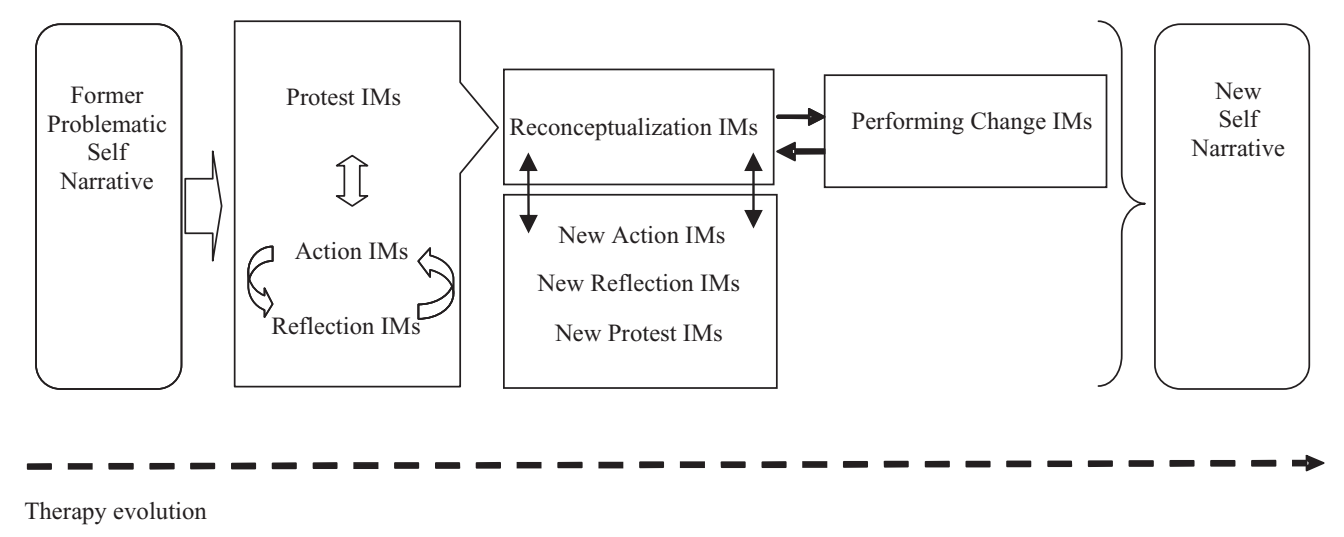

Figure 1. Heuristic model of change. 
process of change. In fact, psychotherapy, when successful, involves some form of detachment from the ongoing psychological processes and a kind of meta-observation, often equated with insight (Castonguay \& Hill, 2007). We think that reconceptualization is a particular type of insight, not only involving access to the process of change but also establishing a contrast between past and emergent new self-narrative. Thus, insight is, from our perspective, just one of the necessary ingredients of reconceptualization.

Performing change IMs extend into the future the changes made so far. Therefore, the client anticipates or plans new experiences, projects, or activities based on the changes made. This gives the client the sense that the emerging new self-narrative has a future.

Finally, the model suggests that the gestalt of IMs that emerge along the therapy - in which reconceptualization seems central-allows for the emergence of a new self-narrative. Of course, we are assuming in this model that IMs are actively involved in the change process, instead of merely reflecting the change that is developing, but until now this is an unproven assumption, as we explicitly stated before (Matos et al., 2009), that needs to be addressed in future studies.

\section{The Present Study}

This study is therefore a further test of the flexibility of the method proposed by the IMCS, given that it is the first time that this method has been applied to CCT. Moreover, client-centered therapists, like emotion-focused therapists, are not explicitly guided by the narrative metaphor of psychotherapy.

A main goal of this research is to study the development of IMs in CCT. We hypothesize that the overall pattern of CCT development of IMs is similar to the one found in EFT and NT and suggested by the heuristic model of change presented earlier. CCT considers psychological difficulties as the result of discrepancy between the organismic experiences and the self-concept, the aim of therapy being to bring this internal tension to awareness and shifting to a state of congruency (van Kalmthout, 2007). CCT therapists adopt three core relational attitudes of empathy, unconditional positive regard and congruence. The treatment involves a safe, supportive environment and the therapists' mode of engagement implicates an empathic understanding and validation of a client's internal frame of reference, making them feel worthwhile and valued instead of evaluated (Goldman, Greenberg, \& Pos,
2005; Greenberg \& Watson, 1998). The therapist should promote an environment of trust, empathy, attunement, and validation of what the client is experiencing at the moment. The exploration of live and poignant experience allows the client's symbolization of core meanings that will facilitate the access to adaptive emotions and responses. Given that CCT is the least directive of all treatments studied so far with the IMCS, we speculate that this might appear in the patterns of IMs' emergence. For instance, chair work in EFT is strongly associated with protest IMs (Mendes, Ribeiro, Angus, Greenberg, \& Gonçalves, 2011) and, although we have no empirical findings on this, we suppose that in NT externalization of the problem could also elicit protest IMs. Thus, we wonder how the absence of directive therapeutic strategies will impact the pattern of IMs of the CCT sample. Accordingly, this study will address the following exploratory research questions:

1. Can the IMCS reliably identify IMs in CCT?

2. Are there significant differences in the probabilities of overall IMs occurring in cases with different levels of symptom improvement?

3. Are there significant differences in the probabilities of specific types of IMs occurring in cases with different levels of symptom improvement?

\section{Method}

\section{Clients}

Clients were part of the York I Depression Study (Greenberg \& Watson, 1998), a project designed to assess treatments of major depression comparing 17 emotion-focused and 17 client-centered (CCT) cases. In this study the clients were randomly assigned to one of the two different treatments (EFT or CCT) for 16 to 20 sessions of individual psychotherapy once a week. In the present study, six therapeutic CCT cases were analyzed. These six cases were those with complete transcripts and data sets for intensive process analysis. At the time of the case selection (1995) researchers responsible for the York I project used a combination of pre-post change on the Beck Depression Inventory (Beck, Steer, \& Garbin, 1988; Beck, Ward, Mendelson, Mock, \& Erbaugh, 1961), therapist reports, and supervisor information on the course of therapy, to select these six cases (three poor and three good outcome cases) from the global sample of 17 . All six clients were women (age range $=29-58$ years, $M=43$ years, $S D=11.28$ ), and only one was not 
married. Clients completed an average of 16.83 $(S D=0.98)$ sessions. Table II shows the pre and post BDI scores for the six cases.

\section{Therapists}

Six therapists conducted the therapeutic process of the six clients analyzed in this study. Four of the therapists were female and two were male. They were of varied levels of education, from advanced doctoral students in clinical psychology to $\mathrm{PhD}$ clinical psychologists. All therapists received 24 weeks of training according to the manual devised for the York I Depression study (Greenberg, Rice, \& Elliott, 1993). A fidelity check of treatment adherence was conducted in the original study (Greenberg \& Watson, 1998).

\section{Client-Centered Therapy Treatment}

The CCT treatment in the present study was conducted according to a manual (Greenberg, Rice, \& Watson, 1994) to supplement Rogers (1951) and all CCT therapists attended weekly supervision sessions.

\section{Measures}

Beck Depression Inventory (BDI). The BDI is a well-known 21-item self-report instrument assessing symptoms of depression (Beck et al., 1988; Beck, et al., 1961). The improvement in symptoms was measured with the BDI (see Table II), which was administered pre and post therapy.

Innovative Moments Coding System. The analysis of the process of change involved the coding of these six cases using the IMCS (Gonçalves, Ribeiro, Mendes, et al., 2011). Table I provides definitions and examples of the different types of IMs. In the previous studies IMCS proved to be reliable, with Cohen's Kappa values of .89 in the study by Matos et al. (2009) and .86 in the study by Mendes et al. (2011). In other case studies the values of Cohen's Kappa ranged from .76 (Gonçalves et al., 2010) to .90 (Ribeiro et al., 2009).

Table II. BDI scores

\begin{tabular}{lccc}
\hline Case & $\begin{array}{c}\text { Pre-test } \\
\text { BDI }\end{array}$ & $\begin{array}{c}\text { Post-test } \\
\text { BDI }\end{array}$ & $\begin{array}{c}\text { Improvement } \\
\text { in the BDI }\end{array}$ \\
\hline Case 1 & 24 & 7 & 17 \\
Case 2 & 21 & 12 & 9 \\
Case 3 & 31 & 5 & 26 \\
Case 4 & 19 & 19 & 0 \\
Case 5 & 13 & 9 & 4 \\
Case 6 & 27 & 16 & 11 \\
\hline
\end{tabular}

\section{Procedures}

For the present study, the IMCS was applied to all sessions of the six CCT clients of the York I Project on Depression Study (Greenberg \& Watson, 1998). Therefore, 93 sessions were coded and all the transcripts of these sessions were intensively analyzed. The coding procedure required data analysis by two coders (second and third authors), unaware of the outcome status of the cases. In this sample, coder 1 (third author) coded the entire sample and coder 2 (second author) coded $30 \%$ of the sample (two sessions from the beginning, two sessions from the working phase and two sessions from the final phase of therapy of the six cases). The coders were trained by the authors of the manual and during this period they had weekly meetings with all members of the research team, who were also being trained. Between meetings they coded psychotherapy transcripts from NT and EFT sessions from the previous studies. Thus, the process of training included discussing the manual with the authors, coding transcripts from different samples, and discussing disagreements and misunderstandings in the process of coding until a consensus was established. At the end of the training period the reliability of the coders was assessed by comparing their codes with the codes of expert judges in a set of randomly selected excerpts from dialogs of therapeutic sessions. Coders were considered to be reliable and able to engage in coding the CCT sample if they achieved a Cohen's Kappa higher than 0.75 . The entire training procedure took several weeks of intensive work. The coding of the CCT sample only started after the end of the training process.

Three steps were carried out in the process of coding IMs: (1) a consensual definition of the facets of the problematic self-narrative by the two coders; (2) identification of each IM, and definition of its beginning and end; and (3) categorization of previously identified IMs in terms of type.

Consensual definition of the problems by the two coders. The first step of the process of coding involved a careful reading of all the psychotherapeutic transcripts. Following this initial procedure, coders independently listed the clients' problems (or themes of the problematic self-narrative) that were the target of therapy and then met to discuss their understanding of the clients' problematic selfnarratives. After this discussion, the problems were consensually defined (as closely as possible to the client's discourse). To make this procedure clearer we give an example of the problematic self-narrative identified in the case of Lisa, a well-known EFT client from the York I Depression Study sample 
("The Case of Lisa," 2008; Gonçalves et al., 2010). One of Lisa's problematic self-narrative themes was "Resentment and difficulty in expressing her own feelings":

L: ... maybe that's why I don't tell him [husband] how I really feel inside (sniff) ... yeah, there's, or, um, even though I express it, it's just kind of laughed at.

As we already stated, an IM, by definition, would be an exception to this theme:

L: ...but then my feelings are my feelings and I'm entitled to them.

Identification of innovative moments. In order to allow coders to track IMs, the sessions were independently coded in the order in which they occurred. Coders identified IMs from the transcript when either therapist or client started to talk about any content that is an exception to the different themes that constitute the client's problematic selfnarrative, identifying each IM's onset and offset. IMs contained both client and therapist turn-taking, since from our perspective change is co-constructed between therapist and client (Angus, Levitt, \& Hardtke, 1999). Thus, the IMs could result from questions or tasks suggested by the therapist, but they were only coded as IMs if the client accepted the therapist's formulation and elaborated on them. For instance, if the therapist posed a question that contained an IM and the client denied it or did not elaborate on it in some way it was not coded.

Categorization of one of the five types of IMs and definition of its salience. After identifying IMs, coders had to identify which type of IM was present (e.g., action, reflection). In order to measure IMs' salience, when we use transcripts (instead of audio/video tapes), as in this study, we measure the percentage of words involved in the IMs. Therefore, salience is a measure of the IMs' length in the transcript. We computed for each client the following measures:

1. Salience of each type of IM (e.g., action, reflection) for each session, calculated as the percentage of words involved in each type of IM per session.

2. Salience for overall IMs, independently of the type, for each session. This is the sum of the five types' salience, calculated as the sum of all words involved in the overall IMs of a given session.
3. Mean salience for the entire treatment, per type and overall IMs, calculated as a mean of the percentage of each type (derived from point 1 ) and overall IMs (derived from point 2).

\section{Results}

\section{Can the IMCS Reliably Identify IMs in CCT?}

Inter-coder agreement on the salience of IMs was calculated as the overlapping words identified by both coders (coder 1 and 2) divided by the total amount of words identified by either coder. The percentage of agreement on overall salience of IMs was $86 \%$, meaning that in $86 \%$ of the text composing the transcripts the coders agreed on the presence of IMs, independently of the specific type. For studying inter-agreement on IM types we used Cohen's Kappa, which in this sample was .97, showing a strong agreement between coders (Hill \& Lambert, 2004). The $30 \%$ of sessions that were used to establish reliability correspond to $36 \%$ of IMs, which are 314 IMs out of 869 IMs. In the next two sections the purpose of the analyses was to provide a descriptive profile of IMs.

\section{Are There Significant Differences in the Probabilities of Overall IMs Occurring in Cases with Different Levels of Symptom Improvement?}

Instead of comparing good with poor outcome cases as was done in other studies with IMs (Matos et al., 2009; Mendes et al., 2010), we worked with the entire sample, without any sort of categorization into good and poor outcome cases, using a generalized linear model of analysis. For the analysis of these data we considered each type of IM independently of the others. Therefore, we considered the salience of a certain type of IM as the response variable, and modeled the probability of that type of IM occurring, given the explanatory variables (time, from session 1 to the last one; the improvement in symptoms; and the interaction of time with the improvement in symptoms).

Consider the case of a binary response variable $0 / 1$ corresponding with the non-occurrence of an IM or the occurrence of an IM of a certain type. We treated this as a random variable with Bernoulli distribution, and were interested in inferring the probability parameter associated with this distribution. Therefore, this probability is the probability of an IM occurring. We fitted a generalized linear mixed effects model to the data, including a subject-specific random effect to take into account variability among 
individuals. That is, measurements coming from a same subject were expected to be correlated.

We then assumed, in accordance with the literature, that

$\mathrm{P}$ (occurrence of an IM of a certain typeexplanatory variables) $=\mu$

where the explanatory variables have a linear effect on the probability through a link function so that

$$
\mu=(\exp (\eta)) /(1+\exp (\eta))
$$

Therefore, the interpretation of $\eta$ is the logarithm of the odds ratio, between occurrence and non-occurrence of an IM; that is,

$$
\eta=\log (\mu /(1-\mu))
$$

The explanatory variables were then included:

$$
\eta=\beta \times \mathrm{X}
$$

where the vector $\mathrm{X}$ is of all the significant explanatory variables, and $\beta$ the vector of the parameters to be estimated.

When fitting the data to this model, we ended up with the selected model, which included only the significant explanatory variables; that is,

$$
\begin{aligned}
\eta= & \beta 0+\beta 1 \times \text { Session }+\beta 2 \times \text { Session }^{2}+\beta 3 \times \\
& (\text { BDI_pre }- \text { BDI_pos })+\beta 4 \times \text { Session } \\
& \times(\text { BDI_pre }- \text { BDI_pos }),
\end{aligned}
$$

in which $\beta 1 \times$ session is the effect of time (session 1 to the last session), $\beta 2 \times$ Session $^{2}$ is the quadratic function of time, $\beta 3 \times($ BDI_pre - BDI_pos) is the improvement in symptoms (that is, BDI initial score minus BDI final score), and finally $\beta 4 \times$ Session $\times($ BDI_pre - BDI_pos) is the interaction of time with the improvement in symptoms.

The data for each type of IM were modeled independently.

Thus, this GLM model allowed us to analyze the above parameters for the probability of occurrence of overall IMs, as well as each specific type of IM (e.g., action, reflection). Let us clarify these parameters further. With parameter $1(\beta 1 \times$ session $)$ we were able to study how the probability of IMs occurring is affected by time, allowing us to check if the probability increased or decreased along the treatment. Parameter $2\left(\beta 2 \times\right.$ Session $\left.^{2}\right)$ was inserted after several exploratory analyses that made it clear that the data were better modeled if we considered this parameter; that is, the data fitted a parabola (when the parameter is positive the data has a $U$ shape, when it is negative the shape is an inverted $U$ ). Parameter $3(\beta 3 \times($ BDI_pre BDI_pos)) allowed us to study the impact of symptom improvement on the probability of IMs occurring. Finally, parameter 4 $(\beta 4 \times$ Session $\times($ BDI_pre BDI_pos) $)$ allowed us to analyze the interaction between time and symptom improvement. That is, symptom improvement may not had the same impact on the probability of IMs occurring during treatment (it may change its rate).

The results for the overall salience are presented in Figure 2, in which the $y$ axis represents the probability of overall IMs occurring and the $x$ axis therapy sessions over time. In Figure 2, the gray gradient represents the degree of pre-post improvement in BDI scores. Accordingly, the darker line represents the case with least improvement (case 4 with zero points in the pre-post BDI difference) and the lighter line represents the case with greatest improvement (case 3 with 26 points in the pre-post BDI difference). The degrees of gray in between these extremes represent the rest of the cases (see Table II for the degree of change in all cases). Please note that all the figures presented below have the same structural features, that is, in all of them the gradients of gray represents the pre-post BDI difference.

The GLM model for overall IMs had significant effects for all the parameters described above. The effect of time (sessions progression) on the probability of IMs occurring was significant and negative $(p<.0001)$, which means that their salience decreased from the beginning and then increased again after the middle therapy, given the positive quadratic effect (in the shape of a parabola) of time $(p<.0001)$. In fact, the quadratic effect shows a decrease in the probability of IMs occurring until session 6, with a clear increase after that point (Figure 2). More importantly, the cases with a

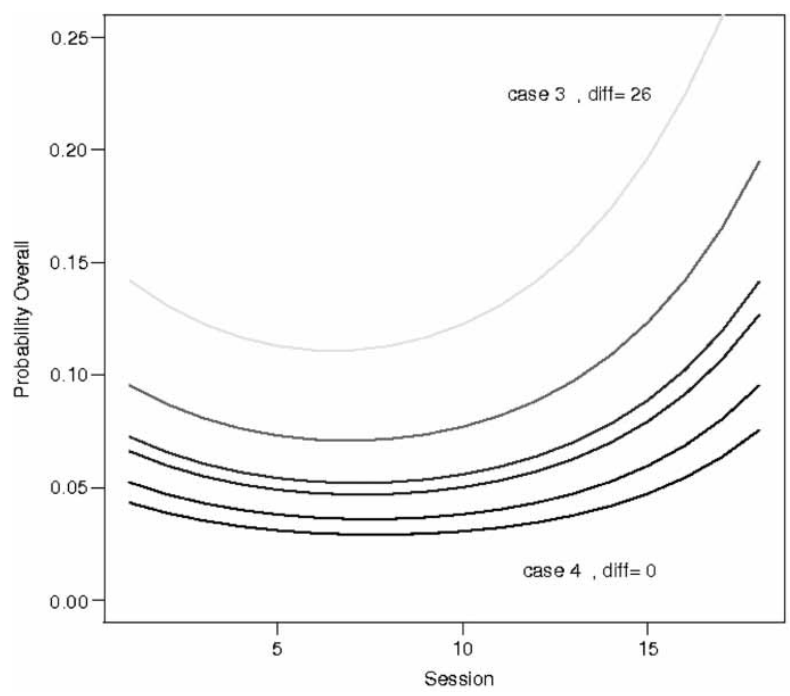

Figure 2. Probabilities of overall IMs. Note: Only the cases (3 and 4) with extreme pre-post differences in BDI are labeled in the figure. The gradient of grey represents the degree of differences, being darker for smaller difference and lighter for bigger difference. 
greater improvement in symptoms had a higher probability of producing IMs $(p<.0001)$. For instance, in the last session the case with the greatest improvement (26 points on the BDI) had a four times higher chance of producing IMs than the case with the least improvement (zero points on the BDI). Thus, whereas the former had a probability of $26 \%$ of producing IMs in the last session, the latter had only a $6.5 \%$ probability (Figure 2 ). There was also a significant interaction $(p<.0001)$ between time and the improvement of symptoms. This means, as can be seen in Figure 2, that cases with greater improvement changed the probability of having IMs with a higher rate over time than cases with less improvement (note that the lighter curve is more pronounced than the darker one).

\section{Are There Significant Differences in the Probabilities of Specific Types of IMs Occurring in Cases with Different Levels of Symptom Improvement?}

The first interesting result was that the probabilities of action, protest and performing change IMs were lower than those of reflection and reconceptualization, as can be seen in Figures 3-7 (note the very different scales). For instance, the highest probability of action IMs occurring was about $1 \%$ (occurring in the last session for the case with the greatest improvement), whereas for reflection IMs it was about $12.5 \%$ (case with the highest improvement, in both the initial and the final session). Thus, in this sample the occurrence of reflection and reconcep-

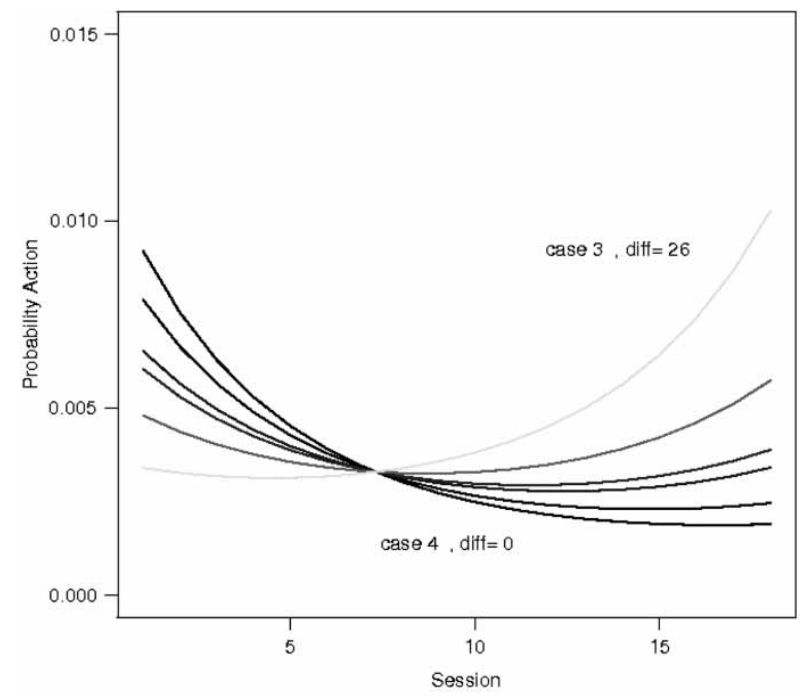

Figure 3. Probabilities of action IMs. Note: Only the cases (3 and 4) with extreme pre-post differences in BDI are labeled in the figure. The gradient of grey represents the degree of differences, being darker for smaller difference and lighter for bigger difference.

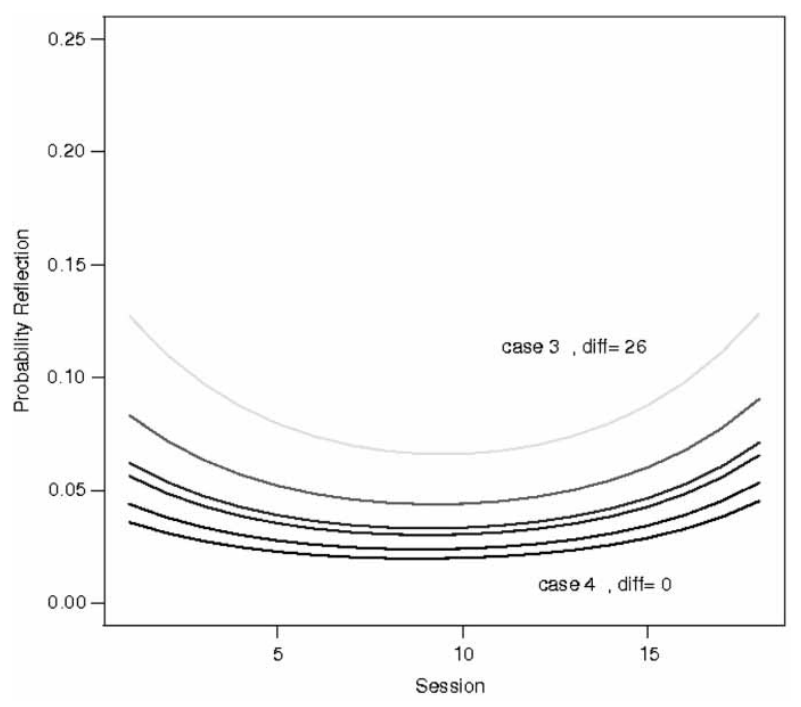

Figure 4. Probabilities of reflection IMs. Note: Only the cases (3 and 4) with extreme pre-post differences in BDI are labeled in the figure. The gradient of grey represents the degree of differences, being darker for smaller difference and lighter for bigger difference.

tualization IMs was much higher than action, protest and performing change IMs. We have done a Wilcoxon test to confirm this pattern and the result shows that in fact the salience of action, reflection and protest IMs was significantly lower than the salience of reflection and reconceptualization IMs $(Z=-2.201 ; p=.028)$.

The development of action IMs can be seen in Figure 3. As occurs with the overall IMs, the probability of action IMs occurring had a significant negative effect of time $(p<.0001)$, and a positive

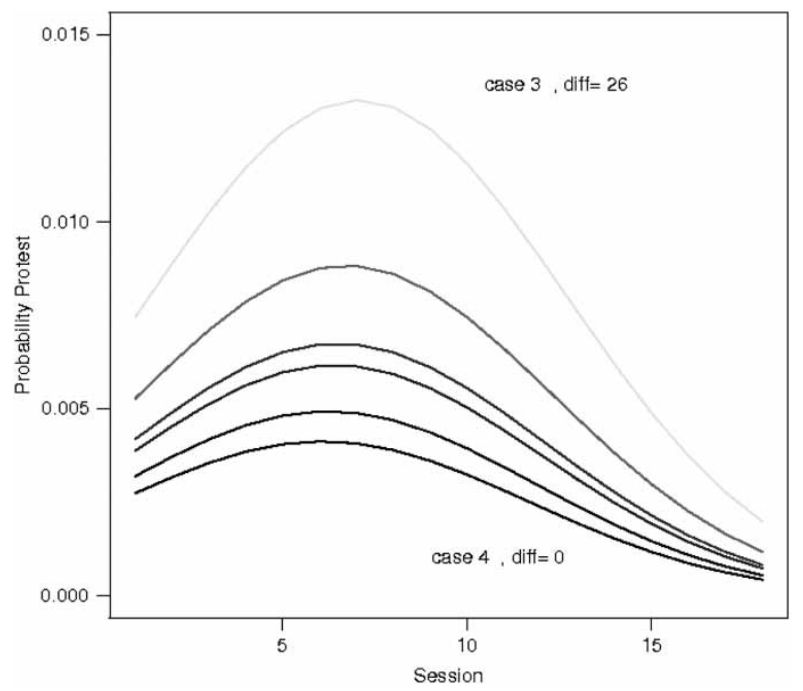

Figure 5. Probabilities of protest IMs. Note: Only the cases (3 and 4) with extreme pre-post differences in BDI are labeled in the figure. The gradient of grey represents the degree of differences, being darker for smaller difference and lighter for bigger difference. 


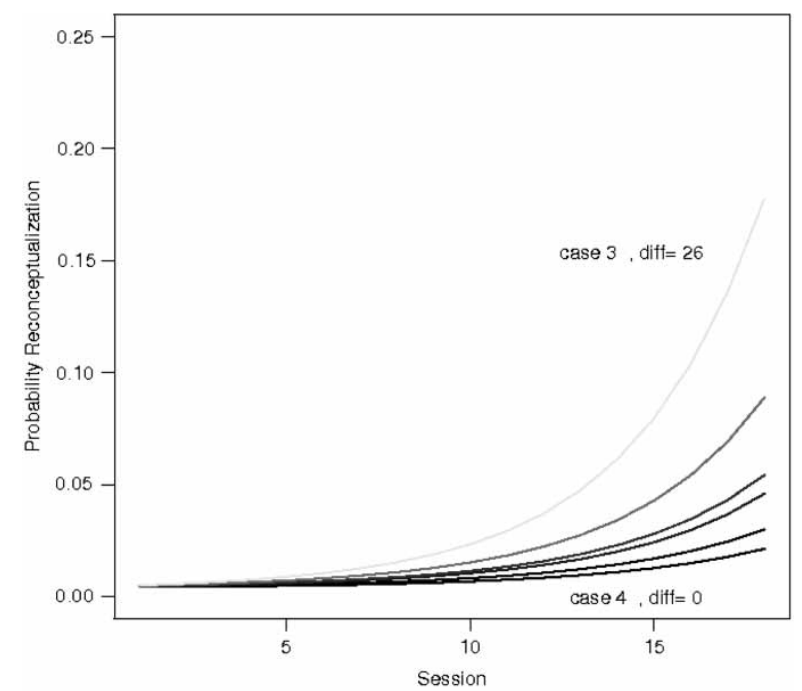

Figure 6. Probabilities of reconceptualization IMs. Note: Only the cases ( 3 and 4 ) with extreme pre-post differences in BDI are labeled in the figure. The gradient of grey represents the degree of differences, being darker for smaller difference and lighter for bigger difference.

quadratic effect of time $(p<.0001)$. This means that the probability of action IMs occurring decreased from the beginning of treatment and then increased again with time. There was no significant effect of the improvement of symptoms in the probability of action IMs occurring $(p=.094)$, but there was a significant effect of the interaction between improvement and time $(p<.0001)$. This means that cases with greater improvement changed the probability of having action IMs with a higher rate than cases with less improvement.

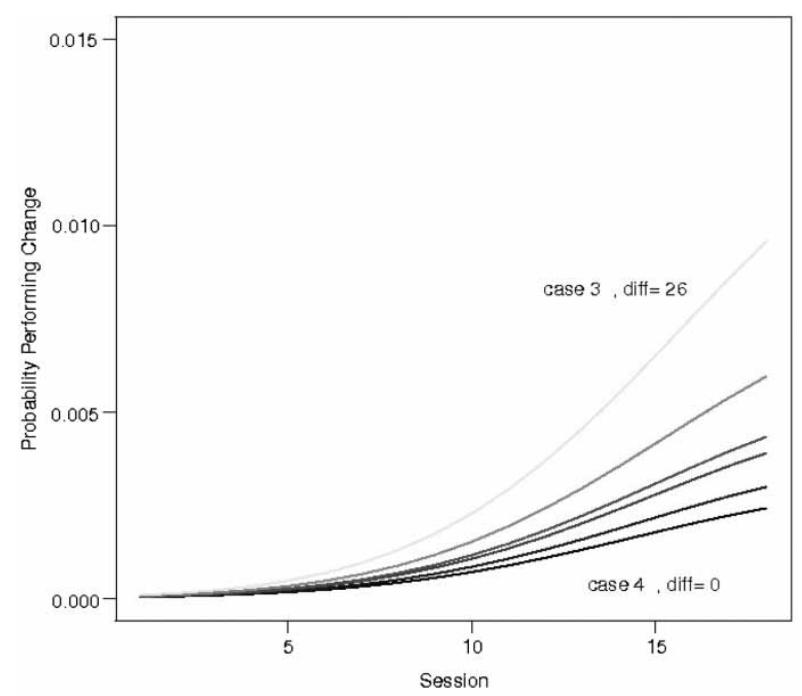

Figure 7. Probabilities of performing change IMs. Note: Only the cases (3 and 4) with extreme pre-post differences in BDI are labeled in the figure. The gradient of grey represents the degree of differences, being darker for smaller difference and lighter for bigger difference.
Reflection IMs (Figure 4) were the most common IMs in this sample. The pattern of the probabilities of reflection IMs across time was similar to the pattern of overall IMs in several respects. There was a significant negative effect of time $(p<.0001)$ and a positive quadratic effect of time $(p<.0001)$. This means that there was a decrease from the beginning of treatment of the probability of reflection IMs occurring and that in the middle of the treatment the probability started to increase. There was no effect of the improvement of symptoms $(p=.0513)$ but there was a significant effect of the interaction between the improvement of symptoms and time $(p<.0001)$. Again, this last result means that the probabilities of cases with different improvement levels changed at different rates (once again the darker line is flatter than the lighter line).

Protest IMs (Figure 5) had a pattern clearly distinct from the ones we described before. This is because their evolution had the shape of an inverted U. In fact the parameter of time was significant and positive $(p<.0001)$, and the quadratic effect of time was also significant but negative $(p<.0001)$. Thus, with these IMs, the probability increased until session 7, after which it started to decrease. Once again there was no effect of symptom improvement $(p=.3580)$, but there was an effect of the interaction between symptom improvement and time $(p=.0015)$. As before, this means that the rate of change in the probabilities was greater for cases with greater improvement in symptoms than cases with less improvement.

The probability of reconceptualization IMs occurring was not affected by time $(p=.101)$, but there was a significant positive effect of the quadratic function of time $(p<.0001)$. This means, as can be seen in Figure 6, that the probability of these IMs occurring did not change across time (the lines are flat, with a value near to zero) until about session 10, in all cases. After this point the probability of reconceptualization IMs occurring started to increase, reaching close to $20 \%$ in the last session. Moreover there was no effect of symptom improvement $(p=.958)$, but there was an effect of the interaction between time and symptom improvement $(p<.0001)$. This means that the rate of increase in the probabilities of reconceptualization IMs occurring was higher in cases with greater symptom improvement (darker lines are flatter).

Performing change IMs (Figure 7) have a similar shape to reconceptualization IMs, but the probabilities of emergence of performing change were much lower than for reconceptualization, as we stated earlier (note the different scales). There was a significant positive effect of time $(p<.0001)$ and a significant negative quadratic effect of time 
$(p<.0001)$. This means that performing change IMs increased during treatment, but they had a clear quadratic effect that is captured in Figure 7 in the evolution after session 7 or 8 . The other parameters were not significant: there was no effect of symptom improvement $(p=.787)$, nor interaction of time with symptom improvement $(p=.175)$.

\section{Discussion}

The first meaningful finding is that, as occurred in other studies, IMs can be reliably identified in CCT transcripts, allowing the study of how innovations develop in therapeutic conversation. As with the EFT sample, IMs emerge in a modality of therapy in which the therapist has no explicit agenda for producing innovative moments, as occurs in NT.

Regarding the evolution and the patterns of IMs across time, this study is partly coincident with other studies, as we will discuss below. Still, the different methodology makes it impossible to perform a direct comparison, while facilitating the discovery of different IM patterns.

The probability of overall IMs occurring is significantly predicted by symptom improvement, which is consistent with prior studies (Matos et al., 2009; Mendes et al., 2010) that found a significant difference between good and poor outcome cases in overall IMs, both in EFT and NT. However, the probabilities of specific types of IMs - such as reconceptualization and performing change IMsdo not appear to be associated with symptom improvement, as was evidenced in previous treatment samples. However, the probability of all IM types occurring, except performing change IMs, is significantly associated with the interaction between symptom improvement and time. This means that for all IMs, except for performing change, despite the fact that symptom improvement did not predict a higher probability of IM occurrence, the probability of the emergence of IMs as the treatment unfolds increases more for cases which evidence greater symptom improvement at treatment termination. In previous studies (Matos et al., 2009; Mendes et al., 2010) we found no differences in action, reflection and protest IMs between good and poor outcome cases. With this methodology we find that even for these IMs the pattern of emergence is different, during treatment, for cases with greater improvement compared with cases with less improvement.

The patterns of change, as observed in Figures $3-7$, are generally coincident with prior studies. Action, reflection and overall IMs have an increase in the middle of treatment. The probabilities for the occurrence of reconceptualization and performing change IMs are almost zero until the middle of therapy, and then increase until the end of treatment. Protest IMs, although with a very low salience, have an evolution similar to what was observed in EFT (Mendes et al., 2011). They increase until the middle of treatment, and then decrease until the end. We speculated previously (Mendes et al., 2011) that this pattern may be important in the development of change, given that protest IMs involve a refusal of the problematic selfnarrative, probably necessary to ignite change, but after the middle of therapy they are replaced, in good outcome cases, by reconceptualization IMs, which sustain change until the end of treatment.

One interesting result, completely new, given the longitudinal nature of this methodology, is the decrease in probabilities of action, reflection and overall IMs occurring from the beginning which increase after the middle of treatment. We speculate that the higher probability of these IMs occurring at the beginning of therapy is partly due to a high expectation of change that clients may have when starting therapy (Lambert \& Ogles, 2004; Frank \& Frank, 1991), which is followed by the need to work through difficult personal issues in psychotherapy and the consequent decrease in the probabilities of IMs emerging. When these issues are in the process of being addressed successfully the probability of IMs occurring increases once again (and at this time reconceptualization and performing change IMs also increase).

The results for performing change IMs are very interesting, given that they contradict our expectations. There is no association of these IMs with symptom improvement (like the other types of IMs), nor with the interaction of time with symptom improvement. One possible interpretation is that the absence of these effects might be due to the low occurrence of these IMs. Another possibility is that change in CCT emphasizes reflection and reconceptualization IMs, given the absence of more directive therapeutic strategies. In a previous study (Santos et al., 2009) it was found that action and performing change formed a cluster of IMs centered on action; reflection, protest and reconceptualization formed another cluster more centered on meaning. Perhaps change in CCT is mainly achieved through constructing innovations centered more on meaning and less on action. This means that, contrary to what we expected, meaningful change can occur without performing change IMs.

Finally, despite the commonalities with other studies previously mentioned, the overall salience of IMs is very low when compared with the EFT sample. EFT's good outcome group had a mean of $30.3 \%(S D=4.02)$, whereas poor outcome had a 
mean of $8.9 \%(S D=5.97)$ (Mendes et al., 2010). This is very different from CCT, in which the good outcome group had a mean of $11.13 \%(S D=5.50)$ and the poor outcome group had a mean of $5.82 \%$ $(S D=3.74)$. One possible interpretation for this difference between EFT and CCT has to do with the use of emotion-focused techniques that might enhance the emergence of IMs in EFT. Several EFT case-studies (e.g., Gonçalves et al., 2010) have suggested that active techniques like chair work elicited a considerable number of IMs. As clientcentered therapists are more focused on the therapeutic relational conditions of empathic attunement, unconditional acceptance and positive regard (Rogers, 1951), perhaps they do not risk eliciting innovations (given that it could compromise the relational conditions), but support them when they are proposed by the client. This difference in overall IMs is also reflected, as we stated above, in the reduced presence of action, protest and performing change IMs. Of course, another possible interpretation is the inability of IMCS to capture all the change involved in CCT. However, we suspect that if in CCT other forms of innovation emerged outside the five type categories of the IMCS this would translate into reliability problems, which is not the case in this study. Moreover, the difference in the overall emergence of IMs between EFT and CCT is congruent with previous findings from Greenberg and Watson's (1998) study on this sample: "The addition of the active experiential interventions to the purely clientcentered treatment appears to facilitate greater change at termination in interpersonal problems, self-esteem, and general distress" (p. 220).

The results from this study, as well as from former studies done with the IMCS (Matos et al., 2009; Mendes et al., 2010), suggest that one commonality of successful psychotherapy is the higher presence of overall IMs and the higher presence of reconceptualization IMs. At this point in our research we are not sure why reconceptualization seems so central to the change process. We offered in the introduction several speculative possibilities about its relevance, but more research is needed to ground these claims empirically.

The size of the analyzed sample is one of the major limitations of the present study, making its conclusions limited and exploratory. The study demonstrates, however, the applicability of IMCS to a new sample, replicating several previous findings. Future research with the IMCS could have important clinical implications, showing how therapists elicit and sustain the construction of IMs in good outcome cases and fail to do so in unsuccessful therapy. Another limitation results from the coding procedures, given that the entire sample was only coded by one coder, and the second coder only coded $30 \%$ of the sessions. In spite of this limitation, this percentage of sessions involved 314 IMs (out of 869 IMs) which means that the Cohen's Kappa refers to a large number of coding decisions.

A final limitation is related to the unproven assumption that IMs are change process variables. In fact, they may simply reflect change as it occurs. Future research needs to address this topic.

Despite this study's limitations, these results could suggest that the addition of emotion-focused techniques, as proposed by Greenberg and colleagues (Elliott et al., 2004; Greenberg et al., 1993; Greenberg \& Watson, 2006) in the EFT manual, could increase the change potential of humanisticbased therapies.

\section{Acknowledgements}

This article was supported by Portuguese Foundation for Science and Technology Grant No. PTDC/PSI-PCL/121525/2010 (Ambivalence and unsuccessful psychotherapy).

\section{References}

Angus, L., \& McLeod, J. (Eds.). (2004). The handbook of narrative psychotherapy: Practice, theory and research. London: Sage.

Angus, L., Levitt, H., \& Hardtke, K. (1999). The narrative processes coding system: Research applications and implications for psychotherapy practice. Fournal of Clinical Psychology, $55,1255-1270$.

Baerger, D.R., \& McAdams, D. (1999). Life story coherence and its relation to psychological well-being. Narrative Inquiry, 9, 69-96.

Beck, A.T., Steer, R.A., \& Garbin, M.G. (1988). Psychometric properties of the Beck Depression Inventory: Twenty-five years of evaluation. Clinical Psychology Review, 8, 77-100.

Beck, A.T., Ward, C.H., Mendelson, M., Mock, J., \& Erbaugh, J. (1961). An inventory for measuring depression. Archives of General Psychiatry, 4, 561-571.

Castonguay, L.G., \& Hill, C.E. (Eds.) (2007). Insight in Psychotherapy. Washington DC: American Psychological Association.

Cunha, C., Gonçalves, M.M., Valsiner, J., Mendes, I., \& Ribeiro, A.P. (in press). Rehearsing renewal of identity: Reconceptualization on the move. In M.C. Bertau, M.M. Gonçalves, \& P. Raggat (Eds.), Dialogic formations: Investigations into the origins and development of the dialogical self. Charlotte, NC: Information Age Publishing.

Dimaggio, G. (2006). Disorganized narratives in clinical practice. fournal of Constructivist Psychology, 19, 103-108.

Elliott, R., Watson, J.C., Goldman, R., \& Greenberg, L.S. (2004). Learning emotion-focused therapy: the process-experiential approach to change. Washington DC: American Psychological Association.

Engle, D., \& Arkowitz, H. (2008). Viewing resistance as ambivalence: integrative strategies for working with ambivalence. Fournal of Humanistic Psychology, 48, 389-412.

Frank, J.D., \& Frank, J. (1991). Persuasion and Healing: A Comparative Study of Psychotherapy (3rd ed.). Baltimore, MD: Johns Hopkins University Press. 
Goldman, R.N., Greenberg, L.S., \& Pos, A.E. (2005). Depth of emotional experience and outcome. Psychotherapy Research, 15, 248-260.

Gonçalves, M.M., \& Ribeiro, A. (2012). Narrative processes of innovation and stability within the dialogical self. In H.J. M. Hermans \& T. Gieser (Eds.), Handbook of Dialogical Self Theory (pp. 301-318). Cambridge: Cambridge University Press.

Gonçalves, M.M., Matos, M., \& Santos, A. (2009). Narrative therapy and the nature of "innovative moments" in the construction of change. Fournal of Constructivist Psychology, $22,1-23$.

Gonçalves, M.M., Mendes, I., Ribeiro, A., Angus, L., \& Greenberg, L. (2010). Innovative moments and change in emotion-focused therapy: The case of Lisa. Fournal of Constructivist Psychology, 23, 267-294.

Gonçalves, M.M., Ribeiro, A., Conde, T., Matos, M., Santos, A., Martins, C., \& Stiles, W.B. (2011). The Role of Mutual InFeeding in Maintaining Problematic Self-Narratives: Exploring one Path to Therapeutic Failure. Psychotherapy Research, 21, $27-40$.

Gonçalves, M.M., Ribeiro, P.A., Mendes, I., Matos, M., \& Santos, A. (2011). Tracking novelties in psychotherapy process research: The Innovative Moments Coding System. Psychotherapy Research, 21, 497-509.

Greenberg, L.S., Rice, L.N., \& Elliott, R. (1993). Facilitating emotional change: The moment-by-moment process. New York: The Guilford Press.

Greenberg, L., Rice, L., \& Watson, J. (1994). Manual for clientcentered therapy. Unpublished manuscript. York University: Toronto.

Greenberg, L.S., \& Watson, J. (1998). Experiential therapy of depression: Differential effects of client-centred relationship conditions and process interventions. Psychotherapy Research, 8, 210-224.

Greenberg, L.S., \& Watson, J.C. (2006). Emotion-focused therapy for depression. Washington DC: American Psychological Association.

Hastie, T., \& Tibshirani, R. (1990). Generalized additive models, Volume 43 of Monographs on statistics and applied probability. London: Chapman \& Hall

Hill, C.E., \& Lambert, M.J. (2004). Methodological issues in studying psychotherapy processes and outcomes. In M.J. Lambert (Ed.), Bergin and Garfield's Handbook of psychotherapy and behaviour change (5th Ed., pp. 84-135). New York: John Wiley \& Sons.

Jacobson, N.S., \& Truax, P. (1991). Clinical significance: A statistical approach to defining meaningful change in psychotherapy research. Fournal of Consulting and Clinical Psychology, 59, 12-19.

Keele, L. (2008). Semiparametric regression for the social sciences. New York: John Wiley \& Sons.

Lambert, M.J., \& Ogles, B.M. (2004). The efficacy and effectiveness of psychotherapy. In M.J. Lambert (Ed.), Bergin and
Garfield's handbook of psychotherapy and behavior change (5th ed., pp. 139-193). New York: Wiley.

Matos, M., \& Gonçalves, M.M. (2004). Narratives on marital violence: The construction of change through re-authoring. In R. Abrunhosa, R. Roesch, C. Machado, C. Soeiro, \& F. Winkel (Eds.), Assessment, intervention and legal issues with offenders and victims. Brussels: Politeia.

Matos, M., Santos, A., Gonçalves, M.M., \& Martins, C. (2009). Innovative moments and change in narrative therapy. Psychotherapy Research, 19, 68-80.

McAdams, D.P. (1993). The stories we live by: Personal myths and the making of the self. New York: William Morrow.

Mendes, I., Ribeiro, A.P., Angus, L., Greenberg, L., \& Gonçalves, M.M. (2011). Narrative change in emotion-focused psychotherapy: A study on the evolution of reflection and protest innovative moments. Psychotherapy Research, 21, 304-315.

Mendes, I., Ribeiro, A.P., Angus, L., Greenberg, L.S., Sousa, I., \& Gonçalves, M.M. (2010). Narrative change in emotionfocused therapy: How is change constructed through the lens of the Innovative Moments Coding System? Psychotherapy Research, 20, 692-701.

Norcross, J.C., \& Goldfried, M.R. (2005). Handbook of psychotherapy integration. New York: Oxford University Press.

Osatuke, K., \& Stiles, W.B. (2006). Problematic internal voices in clients with borderline features: An elaboration of the assimilation model. Fournal of Constructivist Psychology, 19, 287-319.

Ribeiro, A.P., Gonçalves, M.M., \& Ribeiro, E. (2009). Processos narrativos de mudança em psicoterapia: Estudo de um caso de sucesso de terapia construtivista [Narrative processes of change in psychotherapy: A good outcome case of constructivist therapy]. Psychologica, 50, 181-203.

Ribeiro, A., \& Gonçalves, M.M. (2010). Innovation and stability within the dialogical self: The centrality of ambivalence. Culture E Psychology, 16, 116-126.

Rogers, C.R. (1951). Client-centered therapy. Boston: Houghton Mifflin.

Santos, A., Gonçalves, M.M., \& Matos, M. (2011). Innovative moments and poor outcome in narrative therapy. Counselling Psychotherapy and Research, 11, 129-139.

Santos, A., Gonçalves, M., Matos, M., \& Salvatore, S. (2009). Innovative moments and change pathways: A good outcome case of narrative therapy. Psychology and Psychotherapy: Theory, Research and Practice, 82, 449-466.

Sarbin, T.R. (1986). The narrative and the root metaphor for psychology. In T.R. Sarbin (Ed.), Narrative psychology: The storied nature of human conduct (pp. 3-21). New York: Praeger.

van Kalmthout, M. (2007). The process of person-centered therapy. In M. cooper, M. O'Hara, P.F. Schmid, \& G. Wyatt (Eds.), (pp. 221-229). New York: Palgrave Macmillan.

Watson, J.C., \& Greenberg, L.S. (1996). Pathways to change in psychotherapy of depression: Relating process to session change and outcome. Psychotherapy Research, 33, 262-274.

White, M., \& Epston, D. (1990). Narrative means to therapeutic ends. New York: Norton. 